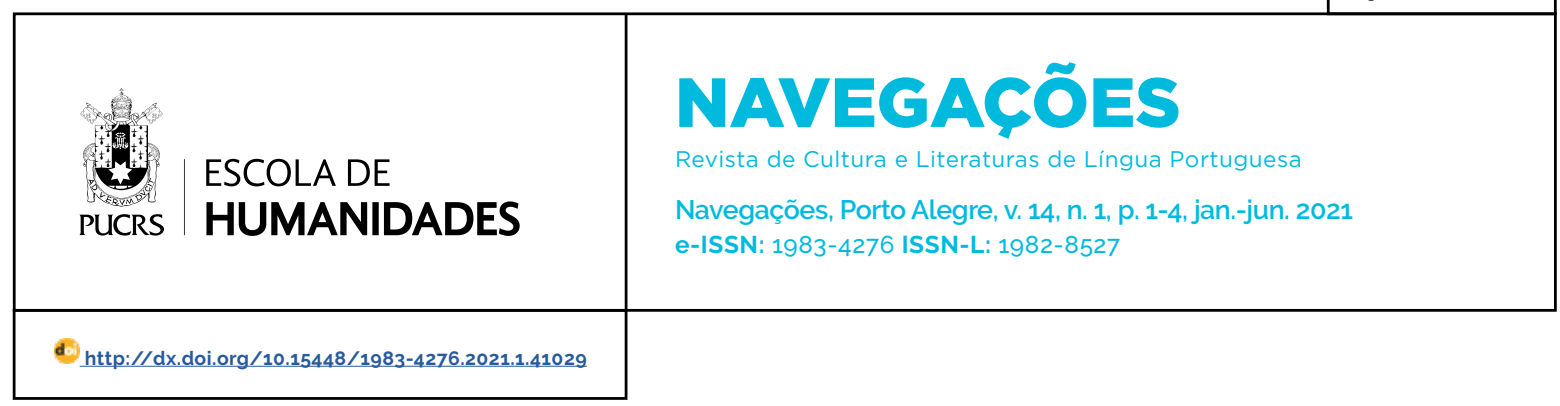

SEÇÃO: RESENHA

\title{
As palavras sangradas de Márcia Barbosa
}

The bleeding words of Márcia Barbosa

\section{Paulo Ricardo Kralik Angelini ${ }^{1}$ \\ orcid.org/0000-0002-7096-0109 \\ paulo.angelini@pucrs.br}

Recebido em: 30 maio 2021. Aprovado em: 4 jun. 2021 Publicado em: 18 agos. 2021.

\section{(c) (1)}

Artigo está licenciado sob forma de uma licença Creative Commons Atribuição 4.0 Internacional.
Professora universitária com sólido percurso no ensino e na pesquisa, Márcia Barbosa descortina-se poeta com Duas fomes, em 2017. E agora, em meio à pandemia, publica o seu segundo livro de poesia. Talvez seja possivel perseguir algumas pistas sobre essa fome (nova e própria) de escrita, depois de anos de leituras, análises e textos sobre as palavras dos outros. Assumir-se poeta, no espanto de uma vocação que cutuca o silêncio e a folha em branco, e escrever poesia como quem rascunha um novo caminho, são exercícios que surgem desenhados em No faro das migalhas, sua mais recente obra. Aqui, o eu lírico apresenta a poesia que nasce em um estalo na descoberta do oficio de poeta: "Nasciam poemas/ e vinham do nada/ foi o que eu me disse na primeira vez (BARBOSA, 2021, p. 82). "As palavras surgem nessa urgência do "corpo inteiro que fervilha/ diante da página vazia/ infinita" (BARBOSA, 2021, p. 85).

Esse espanto do novo laboro faz o eu lírico olhar para o próprio braço adormecido como se não fizesse parte de seu corpo, um outro pedaço de si mesmo: "rente ao caos eu gerava distraída / como se não soubesse quem fazia/ nem como fazer (BARBOSA, 2021, p. 83).

Sublinho aqui a ideia de geração, de gestação, mesmo que extracorpórea. Melhor dito, incorpórea, pois etérea, ainda não totalmente assimilada pelos sentidos. A imagem de uma criação que verte sem pedir licença acompanha muitos dos poemas da obra, que se debruçam sobre esse fazer poético e o assumir-se escritora. Contudo, para preencher a página vazia, para exercitar-se no poema como uma "ginasta no trapézio", a poeta alimenta-se dessa atmosfera nublada e sem sentido em que hoje vivemos, já por mais de um ano. Porque se o mergulho na composição deste No faro das migalhas passa pelo próprio processo de descoberta da necessidade de escrita e pelo resgate da memória, também é técnica de sobrevivência nesses tempos de caos, medo e morte.

A arquitetura de No faro das migalhas estabelece-se em duas seções: "Espectros e a palavra sangrada" e "Quase canto". A segunda parte é o respiro necessário para que a primeira surja, com toda a sua violência assustadoramente plástica, incorporada em palavras que Márcia Barbosa desfere ora como gritos, ora como murmúrios de um cenário onírico, ecos 
que trazem ao leitor uma identificação imediata e, por que não, algum conforto para tudo o que já se viveu - e ainda se vive - em tempos pandêmicos. A seção que inaugura a obra traz, sim, como promete seu título, essa palavra sangrada, o retrato doloroso de um país em triste decomposição. Assim, a obra de Márcia Barbosa é mais uma que se inscreve nesta necessária listagem de uma literatura do desassossego em tempos neofascistas, unindo-se a romances e livros de poemas que têm denunciado o descalabro politico-ideológico dos últimos anos, agravados por uma epidemia sem precedentes.

Não é um exercício fácil revisitar nossas dores na leitura desses poemas. Contudo, é um mergulho que se faz necessário, que ajuda a compreender também o que sentimos e não dizemos, ou não sabemos nomear. O primeiro verso da obra, rico em sonoridade e aliterações, é significativo: "A trava se abrindo trouxe os espectros à sala de estar" (BARBOSA, 2021, p. 17). Os fantasmas assumem seu posto de protagonismo e revivem dramas crônicos, em uma reencenação do velho teatro colonial, um senhor da Casa Grande com o dinheiro na mão, mais uns tantos com o chicote a defenderem a opressão, o moralismo, o conservadorismo, o preconceito, já que: "A encenação levada ao palco é uma reprise/ mas oportunistas e crédulos se exaltam/ eis aí o milagre nacional (BARBOSA, 2021, p. 19).

O milagre nacional sobre o qual o eu lírico se refere vem travestido, por certo, de verde e amarelo e traz esses ícones pátrios em gritos de ordem, "hino entoado com ardor" (BARBOSA, 2021, p. 19), armas em punho, culto a um Deus vingativo e adoração à morte e à violência. Violência, aliás, como fruto de uma sociedade desde sempre desigual, herdeiros dos caçadores de escravos ainda às ruas: "mas o que faz um pescoço debaixo do joelho de um policial?" (BARBOSA, 2021, p. 32). Porque "chicoteado em público/ é sempre o mesmo o bicho abatido no espetáculo (BARBOSA, 2021, p. 33).

A despeito da forte herança que nos cabe, ou talvez justamente por conta dela, os poemas também observam as últimas movimentações políticas; a forma como o sistema encontrou para reproduzir, ainda com mais força, os ressentimentos trancafiados de uma elite que se via alijada do poder, "os parasitas fantasiados de pátria", "sugando o país real" (BARBOSA, 2021, p. 19). Nesse tribunal, todos são denunciados, inclusive os isentos: "Orgulham-se os isentos de não compactuar/ de não ceder./ Olham de cima o inferno/ o mundo concreto do qual se abstêm./ Diante do genocídio/da pátria lesada/ das violações/ dirão, em sua defesa, que têm um álibi (BARBOSA, 2021, p. 25).

Não há defesa, porque "o limbo é o inferno que os persegue" (BARBOSA, 2021, p. 25). Um parasita, um monstro que "se instala em outro corpo" e mata "à míngua o hospedeiro" (BARBOSA, 2021, p. 19).

A poesia de Barbosa assume-se, portanto, como eco de representatividade contra essa espécie de normalização da opressão experenciada hoje em dia: contra o machismo, o racismo, a violência contra os excluidos. Décadas de luta, décadas de gritos e de tentativas de reeducar os modos que excluem e que matam em sua exclusão parecem implodir. O edifício do respeito e da aceitação das diferenças, que julgávamos já sólido e bem alicerçado, desaba com uma facilidade assustadora frente a novos discursos oficiais e oficiosos, permissivos e preconceituosos, que por sua vez, em uma cadeia reprodutora sem fim, consolidam esse retrocesso que nos atinge, dia a dia.

No faro das migalhas encena, com potência, a denúncia do machismo e do feminicídio, como no poema "Eu vi uma mulher morta", que traz seu verso-título repetido, ecoado por todo o poema, como um daqueles filmes hollywoodianos em que a personagem acorda todos os dias em um mesmo dia, o tempo elástico porque todos os dias iguais. Todos os dias são dias de violência contra a mulher, porque o agressor, "protegido pelo escudo que é sempre o mesmo", "sustenta a farsa": "hoje às oito horas da manhã eu vi uma mulher morta/ o corpo estendido na calçada/ e o assassino com a honra intacta (BARBOSA, 2021, p. 31).

O corpo da mulher estendido em uma repetição de dores diárias, assim como o corpo do negro, porque todos os dias também são dias de violência contra o negro, na violência cotidiana das chacinas: é "sempre a mesma vítima numa 
casa cravejada de balas" (BARBOSA, 2021, p. 33). E a justiça? E a pergunta: "O que faz a menção à raça/ neste exato momento numa sentença judicial? / O que faz um cliente, armado de cartão de crédito e nota fiscal, / ser confundido com assaltante num shopping da capital?/ A pele é uma marca (BARBOSA, 2021, p. 33).

O negro, a mulher, jogados na calçada e em uma reprodução infinita de culpabilização: "Toda mulher é Eva à espera da culpa" (BARBOSA, 2021, p. 28), legitimação das ações destrutivas do patriarcado, que se justifica na morte, no assassinato, na violência desde a infância: "O corpo pequeno/ violado/ era uma dor sitiada" (BARBOSA, 2021, p. 28), que a menina "engolia sem água" (BARBOSA, 2021, p. 28). A menina do poema é cada menina ou mulher cujo livre arbitrio é menos importante do que o filho que carrega, mesmo sendo fruto de violência, neste país, território ocupado, faminto e devastado, que grita a criminalização do aborto, porque: "O corpo, se for de mulher,/ é somente o vaso/ sem alma/ a serviço da espécie/ à disposição do fruto/ este sim pleno, repleto de alma, divino (BARBOSA, 2021, p. 28).

Poemas de forte potência imagética e política, sem nunca cairem no tom de panfleto, porque carregados daquilo que os faz literatura: a linguagem. Linguagem, imagem, sonoridade, que obedecem àquelas sensações resgatadas por Alfredo Bosi, "que integram experiências fundamentais do corpo humano". Quer dizer: "essa radical subjetividade ou, se preferir, essa corporeidade interna e móvel da matéria verbal torna relativa, mediata, simbólica, jamais icônica, a representação do mundo pela palavra" (BOSI, 1977, p. 49), que é uma resposta à experiência vivida. Márcia Barbosa é, como seus leitores, como nós, testemunha diária do horror, por vezes higienizado pela midia, frequentemente solapado pelo poder oficial, e dessa experiência nasce a palavra, como nasceu a flor que rompeu o nojo, o ódio, o asfalto. E "onde morre o asfalto, a matéria começa" (BARBOSA, 2021, p. 106).

A autora também desfila uma série de críticas ao empreendedorismo, a uma sociedade que finge dar oportunidades iguais a todos: "à subserviência chamam de iniciativa" (BARBOSA, 2021, p.
42), quando, na verdade, estimula a segregação daqueles que não fazem parte da familia puro-sangue: "homem, mulher e filhos" (BARBOSA, 2021, p. 26). Um país que censura a palavra, que teme as palavras que subvertem a ordem e provocam a extinção da família e que idolatra a palavra casta.

Não escapam do olhar de Barbosa as redes sociais e suas estratégias cruéis de propagação da mentira, da difamação de verdades científicas em tempos de terra plana, das "máquinas para aparar as arestas" e "revogar a curvatura da Terra" (BARBOSA, 2021, p. 17). Em tempos de "cancelamento" e de violência online. Em tempos de demonização da figura do professor, da cultura e da arte, tempos da censura, do dever e da retidão, de: "proteger os inocentes das figuras sem decoro/ essas que habitam os museus/ e teimam em atravessar despidas mais um século (BARBOSA, 2021, p. 17).

Mais ou menos no caminho daquilo que Christian Dunker pontua em seu livro Paixão da ignorância, quando afirma que o homem se vale do discurso da negação ou do recalque para desconstruir os achados científicos e a educação para o despertar de um senso crítico. Ou seja,

ele recobrirá o vazio com o ódio, que imaginariza o real, ou o amor, que simboliza o imaginário. A ignorância é a realização do simbólico, e quando o simbólico se realiza percebemos que ele é composto de negatividade e não de positividade (DUNKER, 2020, p. 17).

Esse culto ao ódio e ao negativo surge já no primeiro poema, na denúncia de uma série de versos que nos cabem e nos envergonham: "instrumentos para colonizar as almas", "artefatos para amansar a crina dos violinos" (BARBOSA, 2021, p. 17), um discurso hipócrita, já que esses fantasmas trazem valores que são "produtos para consumo alheio" porque "ativados conforme as conveniências e a ocasião" (BARBOSA, 2021, p. 18).

Nesse universo avassalador, surge a força dos dispositivos eletrônicos, aqueles que, de acordo com Dunker, trazem uma "ausentificação de si" (DUNKER, 2020, p. 259), artificio perfeito para a ação dos parasitas, porque vem dos aplicativos, do WhatsApp, da rede social a prova do acontecido: "a situação não ocorreu/ se ocorresse, com o advento do celular,/ alguém teria feito 
uma imagem, registrado o acontecido./ E sem imagem fato não há (BARBOSA, 2021, p. 37).

Na era da pandemia, corpos empilhados nos telejornais, nos fundos dos hospitais, tão longe de nós, assim como estamos longe do toque, do abraço, do afeto, do outro: "Mas de tanto me salvar das superfícies contaminadas/das gotículas de saliva que viajam no espaço/ o que eu vejo são pixels no lugar de poros (BARBOSA, 2021, p. 43).

Marcas dos nossos meses de confinamento, cansados que estamos da "voz com volume regulável", do "universo blindado em alta resolução": "Câmera e microfone, eu dizia,/ Como quem diz/ Para-raios, capa de chuva, botas e sombrinha (BARBOSA, 2021, p. 43).

Lives, aulas remotas, encontros virtuais, eis nossa forma de pedir asilo contra o inimigo onipotente e obscuro.

Um confinamento que também traz um trancar-se por dentro, na busca de resgate, no pedido de socorro que vem de lembranças felizes, composição da segunda seção de No faro das migalhas: a infância, a presença ausente da mãe. os passeios de bicicleta com o pai, o mundo colorido de tecidos, botões e linhas na costura com a tia, costura que se faz também com as palavras. Cerzir a escrita, arrematar o verso, mesmo que uma neblina a memória: "A casa na árvore hospeda o passado no presente/ minha infância suspensa pelas asas / e os ramos da memória cobrindo a moldura/ no quarto andar (BARBOSA, 2021, p. 89).

É na arquitetura do memorado que surge um cotidiano suportável, o café, "um eco de outra espécie" (BARBOSA, 2021, p. 92). É no escondido dentro de nós, lá na caverna (vocábulo-imagem repetido em vários poemas) que vêm os cheiros, os sons, a arte que não se deixa sepultar: o origami, o contrabaixo, o bailarino, a valsa de Camille Claudel. E as gentes, o maestro, o afinador de pianos, o arquiteto, "esse dramaturgo do ar e do concreto" (BARBOSA, 2021, p. 110). São imagens, flashes, cenas de um dia que foi, mas que também ainda virá. Porque nós, apesar de tudo, estamos vivos. Supervivos: "Nós os sobrevividos/ restamos/ permanecidos/ porque nos deixamos viver/ porque ficamos sem sucumbir/ escondidos/ou esquecidos de ruir (BARBOSA, 2021, p. 118).

Após atravessarmos todas as palavras sangradas por Márcia Barbosa, grunhidos do nosso repertório triste e diário, ainda existimos, "escapamos da morte e do desastre". O livro termina com o otimismo dos valentes, no poema "Supervivos", porque nós, às vezes, "transpomos a membrana/ que torna os dias indistintos e sombrios" (BARBOSA, 2021, p. 118). E "transcendidos, criamos" (BARBOSA, 2021, p. 119).

E "se a língua ganha a dimensão da escrita, a escrita toma a dimensão do mundo", já dizem os versos da poeta portuguesa Maria Tereza Horta (2019, p. 171). É na criação de Márcia Barbosa que a palavra caçada (e cassada) é, enfim, recuperada, "adquire matéria sólida", adensa-se e faz-se destroço seguro para resistirmos ao naufrágio.

\section{Referências}

BARBOSA, Márcia. No faro das migalhas. Porto Alegre: Class, 2021.

BOSI, Alfredo. O ser e o tempo da poesia. São Paulo: Cultrix, 1977.

DUNKER, Christian. Paixão da ignorância: a escuta entre psicanálise e educação. São Paulo: Contracorrente, 2020.

HORTA, Maria Tereza. Eu sou a minha poesia. Alfragide: D. Quixote, 2019.

\section{Paulo Ricardo Kralik Angelini}

Doutor em Literaturas em Lingua Portuguesa pela Universidade Federal do Rio Grande do Sul (UFRGS), em Porto Alegre, RS, Brasil; professor na Pontificia Universidade Católica do Rio Grande do Sul (PUCRS), em Porto Alegre, RS, Brasil.

\section{Endereço para correspondência}

Paulo Ricardo Kralik Angelini

Pontificia Universidade Católica do Rio Grande do Sul Escola de Humanidades

Av. Ipiranga, 6681, prédios 8 e 9

Partenon, 90619-900

Porto Alegre, RS, Brasil

Os textos deste artigo foram revisados pela Poá Comunicação e submetidos para validação do autor antes da publicação. 